\title{
Knowledge Management System Pemesanan dan Informasi Makanan pada Bakmi Golek Rawamangun
}

\author{
Geren Widya Agasti ${ }^{1}$; Puput Irfansyah ${ }^{2}$; Eko Harli ${ }^{3}$ \\ ${ }^{1}$ Universitas Indraprasta PGRI \\ ${ }^{1}$ geren.agasti06@gmail.com
}

\begin{abstract}
Bakmi Golek is a restaurant that has been around for a long time and not only provides noodles but other Chinese food. The ordering system at Bakmi Golek Rawamangun is still using a manual system, so the writers assess that there are still several problems, including the food ordering process is still using handwriting, the data storages are still using paper media, data search will take a long time because it must have to find the paper one by one on an archive, and making reports still require a lot of writing, so the data that has been stored in the archive will be lost. The purpose of this research is to provide effective and efficient solutions through KMS to Bakmi Golek Rawamangun employees in order to help improve performance while the staff is working, make KMS at the restaurant, facilitate the users in carrying out buying and selling transactions, data processing and checking sales reports, and present a good ordering system by providing convenience and information for consumers in the food ordering process. The method used in this study is a research and development method with system development using the waterfall method. The result of this research is an application system of ordering and food information based on knowledge management system.
\end{abstract}

Keywords: Knowledge Management System, Bakmi Golek Rawamangun, Java, MySQL, Booking

\begin{abstract}
ABSTRAK
Bakmi Golek merupakan salah satu restoran yang sudah berdiri sejak lama dan tidak hanya menyediakan bakmi tetapi makanan chinesse food lainnya. Sistem pemesanan pada Bakmi Golek Rawamangun masih menggunakan sistem manual, sehingga penulis menilai masih terdapat beberapa masalah, diantaranya proses pemesanan makanan masih menggunakan penulisan tangan, penyimpanan data pada Bakmi Golek Rawamangun masih menggunakan media kertas, pencarian data akan memakan waktu lama karena harus mencari kertas satu per satu pada sebuah arsip, dan pembuatan laporan masih memerlukan banyak penulisan sehingga tidak menutup kemungkinan data yang sudah disimpan dalam arsip akan hilang. Tujuan dari penelitian adalah memberikan solusi yang efektif dan efisien melalui KMS pada karyawan Bakmi Golek Rawamangun dalam rangka membantu meningkatkan kinerja saat menjalankan pekerjaan, membuat KMS pada Bakmi Golek Rawamangun, untuk memudahkan user dalam menjalankan transaksi jual beli, pengolahan data dan pengecekan laporan penjualan dan untuk menyajikan sistem pemesanan yang baik dengan memberikan kemudahan dan informasi untuk konsumen dalam proses pemesanan makanan. Metode yang digunakan pada penelitian ini adalah metode research and development dengan pengembangan sistem menggunakan metode waterfall. Hasil dari penelitian ini adalah sistem aplikasi pemesanan dan informasi makanan menggunakan pendekatan Knowledge Management System.
\end{abstract}

Kata kunci: Knowledge Management System, Bakmi Golek Rawamangun, Java, MySQL, Pemesanan. 


\section{PENDAHULUAN}

Bakmi Golek Rawamangun merupakan salah satu restoran yang sudah berdiri sejak lama dan tidak hanya menyediakan bakmi tetapi juga makanan chinnese food lainnya. Menurut KBBI bahwa pemesanan adalah proses, perbuatan, cara memesan atau memesankan [1].

Secara umum pemesanan adalah pembelian barang atau jasa yang dilakukan sebelum barang dan jasa itu diterima. Proses pencatatan pemesanan masih dalam media kertas dan tidak tersusun dengan baik, sehingga memiliki resiko kesalahan yang dilakukan oleh manusia (Human Error) dengan demikian akan membuat knowledge hilang dan akan menghambat kinerja karyawan. Kurangnya pengetahuan tentang cara memesan dengan cepat dan akurat karena masih dilakukan secara manual, sehingga menimbulkan lambatnya proses layanan. Selain itu, belum adanya knowledge yang terkait tentang bahan makanan yang perlu di ekspose ke pelanggan.

Berdasarkan masalah tersebut, penulis menawarkan sebuah solusi agar memiliki sistem pemesanan yang lebih baik. Solusi yang penulis tawarkan adalah Knowledge Management System pemesanan dan informasi makanan. Dengan adanya sistem ini diharapkan dapat mengatasi masalahmasalah tersebut guna membantu mempermudah mekanisme kinerja di Bakmi Golek Rawamangun. Dengan menerapkan Knowledge Management System (KMS) merupakan upaya untuk menumbuhkan budaya saling berbagi pengetahuan (sharing knowledge) antar individu maupun organisasi [2] dan juga alur komunikasi yang tercipta dari sistem kepada pengguna dapat digunakan untuk saling berhubungan agar penyampaian suatu informasi dapat tersampaikan dengan baik dan jelas [3] begitu juga terorganisir dan efektif [4].

Penelitian terdahulu dan relevan sudah membahas dan membuktikan bahwa KMS memiliki beragam keuntungan untuk pengelola dan penggunanya. Diantaranya di SMAN 4 Tangerang pada tahun 2011 sudah mampu menghasilkan sistem yang memfasilitasi pengguna untuk berkomunikasi dengan pegawai lainnya. Secara garis besar, sistem knowledge management ini dapat melakukan input data, edit data, hapus data, dapat menampilkan data atau tidak serta mampu menyimpan datadata yang suatu saat dibutuhkan kembali [5]. Begitu pun dengan penelitian lain sebelumnya, dengan pengembangan sistem menggunakan model SDLC (System Development Life Cycle) Osaka Ramen Depok pada tahun 2019 telah mampu membuat sistem pemesanan menjadi sistem yang terkomputerisasi sehingga dapat mempercepat proses pemesanan, menghindari kesalahan pesanan, dan pengolahan data laporan pemesanan menjadi lebih mudah. Hasil yang didapat adalah dengan mengimplementasikan sistem pemesanan yang terkomputerisasi dapat membuat proses pemesanan menjadi lebih efektif dan efisien [6].

Implementasi sistem informasi perpustakaan yang ada di Universitas Islam Indragiri menggunakan pemrograman web based sehingga dapat memberikan pelayanan maksimal kepada pengguna perpustakaan, baik pengguna internal maupun eksternal perpustakaan, dengan memberikan pelayanan secara online sehingga koleksi yang ada pada perpustakaan dapat diakses kapan saja dan dimana saja tanpa terpengaruh jarak, ruang dan waktu yaitu dengan memanfaatkan teknologi jaringan internet, maka tujuan ini dapat direalisasikan dengan membangun infrastruktur yang mendukung akses internet. Jika dibandingkan dengan sistem Dekstop, Sistem Web Based tidak memiliki batasan waktu dan tempat untuk mengaksesnya [7].

Hal serupa dilakukan oleh rumah makan Pindang Rajo dimana implementasi KMS dapat membantu membantu mempermudah untuk mencari data dengan cepat, mempermudah untuk melihat menu makanan dan minuman yang sering dipesan oleh pelanggan, membantu mengurangi kesalahan dalam mencatat menu yang dipesan dan dapat membantu dalam proses transaksi pembayaran, yang berguna untuk mengurangi kesalahan pada saat perhitungan total bayar [8]. 
Dari penelitian terdahulu, penulis melakukan penelitian sistem pemesanan makanan dengan pendekatan knowledge management system. Perbandingan dengan studi kasus sebelumnya yaitu, studi kasus dilakukan di Bakmi Golek Rawamangun, hasil pembuatan dari sistem ini yaitu pemesanan makanan berbasis java. Dengan adanya aplikasi ini sistem pemesanan makanan ini dapat melakukan pemesanan secara efisien, dapat mengekspose dan memberikan informasi mengenai bahan makanan yang terdapat didalam menu dan bisa menghasilkan timbal balik berupa pengetahuan baru, terjadinya interaksi knowledge sharing antar produsen dan konsumen.

\section{METODE/PERANCANGAN PENELITIAN}

Model yang digunakan dalam KMS ini menggunakan SECI Model [9].Mengungkapkan dengan menggunakan model ini akan mengkonversikan pengetahuan yang dimiliki seperti memberikan informasi mengenai bahan makanan dan manfaat yang terdapat didalam menu, sehingga pengetahuan dari explicit ke tacit akan berguna bagi pengguna untuk mengetahui informasiinformasi tersebut dalam proses pemesanan.

Adapun tahapan pengembangan sistem pada aplikasi yang penulis buat menggunakan metode waterfall. Metode waterfall adalah metode yang melakukan pendekatan secara sistematis dan urut mulai dari level kebutuhan sistem, tahap analisis, desain, coding, testing, dan maintenance [10].

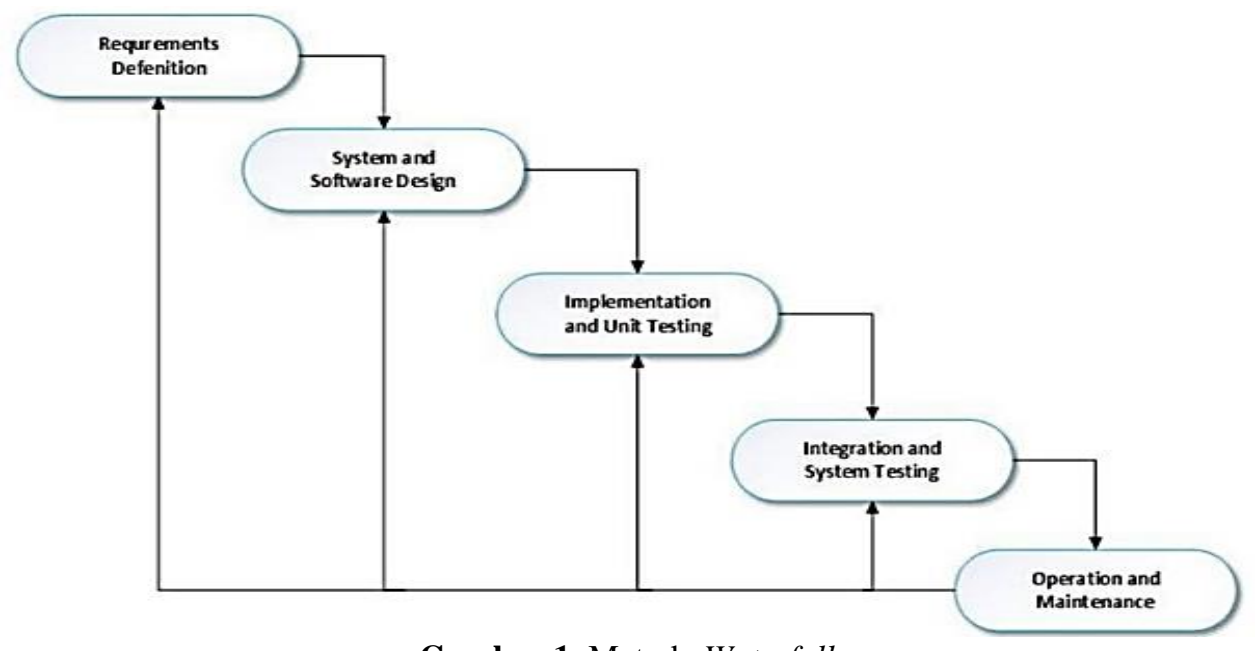

Gambar 1. Metode Waterfall

Sehingga langkah-langkah dalam penelitian KMS pemesanan ini yaitu:

1. Penulis menggunakan dua pendekatan yaitu studi literatur untuk memahami kondisi dan menganalisis kebutuhan serta menggunakan studi lapangan untuk mengamati dampak nyata yang terjadi di lingkungan.

2. Dalam penelitian ini penulis akan merancang desain diagram dan kode program yang dikembangkan menggunakan bahasa pemrograman java.

3. Pada tahap pengembangan, kerangka yang masih konseptual tersebut direalisasikan menjadi produk yang siap di implementasikan.

4. Pada saat pengembangan akhir aplikasi akan di uji coba pada perangkat software. Tahap ini ditujukan untuk memastikan apakah hasil sistem sudah sesuai dengan tujuan yang diharapkan sebelumnya.

5. Ketika sistem telah lulus tahap uji, sistem akan memasuki tahap uji coba lapangan yang bertujuan mengetahui tanggapan para pengguna secara langsung. 


\section{HASIL DAN PEMBAHASAN}

Dalam pandangan [11], oleh Nonaka dan Takeuchi pengetahuan tersebut dapat di konversi dengan empat cara, yang disebut dengan SECI Mode, yaitu: Socialization (S), Externalization (E), Combination (C), dan Internalization (I). Pengetahuan tersebut dapat di konversi dengan empat cara, yang disebut dengan SECI Mode, yaitu: Socialization (S), Externalization (E), Combination (C), dan Internalization (I). Dengan hal ini penulis akan menjelaskan dari keempat model yang terkait dengan hasil penelitian, berikut penjelasannya:

1. Socialization atau Sosialisasi, merupakan suatu konversi pengetahuan antara tacit ke tacit, dengan hal ini peneliti melakukan kegiatan pertemuan antara pihak Bakmi Golek Rawamangun dengan penerima pengetahuan (peneliti).

2. Externalization atau Eksternalisasi, pengubahan pengetahuan tacit ke explicit, peneliti akan menambahkan pengetahuan baru seperti membuat fitur FAQ dalam sistem aplikasi yaitu pelanggan bisa memberikan pendapat, kritik dan saran sehingga pihak Bakmi Golek Rawamangun bisa mengetahui apa saja kekurangan-kekurangan yang ada di restoran tersebut.

3. Combination atau Kombinasi, peneliti akan memasukkan daftar menu beserta gambarnya di dalam aplikasi sehingga pelanggan bisa mengetahui seperti apa makanan yang ingin dipesan. Dari yang sebelumnya daftar menu yang terdapat di Bakmi Golek Rawamangun masih menggunakan cetakan kertas.

4. Internalization atau Internalisasi, suatu proses konversi antara explicit knowledge menjadi tacit knowledge, sebelum melakukan pembuatan sistem pemesanan ini peneliti mempelajari terlebih dahulu apa saja informasi yang ada mengenai Bakmi Golek Rawamangun dalam segi pemesanannya.

Berdasarkan masalah-masalah yang terdapat pada Bakmi Golek Rawamangun, maka penulis memberikan alternatif penyelesaian masalahnya, yaitu :

1. Penulis membuatkan sistem pemesanan berbasis java agar sistem pemesanan pada Bakmi Golek Rawamangun berjalan dengan efektif dan efisien.

2. Menyajikan sistem pemesanan dengan memberikan kemudahan dan informasi seputar bahan makanan untuk konsumen dalm proses pemesanan makanan.

3. Membuat fitur FAQ pada aplikasi yang penulis buat agar pelanggan bisa memberikan pendapat, kritik dan saran kepada pihak Bakmi Golek Rawamangun.

4. Aplikasi yang akan dibuat menggunakan plugin iReport pada sistem untuk pembuatan laporan sehingga akan mempermudah dalam menjalankan transaksi jual beli, pengolahan data dan pengecekan laporan pemesanan.

Umumnya suatu kebutuhan perangkat lunak dapat dikategorikan sebagai kebutuhan fungsional dan non-fungsional. Kebutuhan fungsional menggambarkan apa yang sistem harus lakukan atau sediakan. Sedangkan kebutuhan non fungsional adalah kebutuhan yang menggambarkan bagaimana sistem atau aplikasi bekerja beserta batasan-batasan yang menyertainya dalam menjalankan fungsionalitas sistem [12]. Berikut perbedaan dari sistem dilihat dari setiap kebutuhannya:

Tabel 1. Hasil Analisis Kebutuhan Fumgsional Pengguna

\begin{tabular}{|c|l|}
\hline Nomor & \multicolumn{1}{c|}{ Deskripsi } \\
\hline 1 & Sistem dapat melakukan input data makanan dan minuman \\
\hline 2 & Sistem dapat melakukan pengecekan pesanan dari pelanggan \\
\hline 3 & Sistem dapat melihat pendapat, kritik dan saran dari para pelanggan \\
\hline 4 & Sistem menyediakan fitur penilaian untuk para pelanggan \\
\hline
\end{tabular}


Tabel 2. Hasil Analisis Kebutuhan Non Fungsional Pengguna

\begin{tabular}{|c|l|}
\hline Nomor & \multicolumn{1}{|c|}{ Deskripsi } \\
\hline 1 & Sistem dijalankan oleh software Xampp, Netebans, dan PHP MyAdmin \\
\hline 2 & Info panduan penggunaan \\
\hline 3 & Info mengenai restoran Bakmi Golek Rawamangun \\
\hline
\end{tabular}

Penulis menggambarkan sistem yang diusulkan dalam bentuk DFD (Data Flow Diagram). " $D F D$ adalah model untuk menggambarkan asal dan tujuan penyimpanan data, proses yang akan menghasilkan data dan interaksi antar data yang tersimpan dalam proses tersebut [13].

Berikut adalah gambaran sistem yang diusulkan oleh penulis untuk Bakmi Golek Rawamangun:

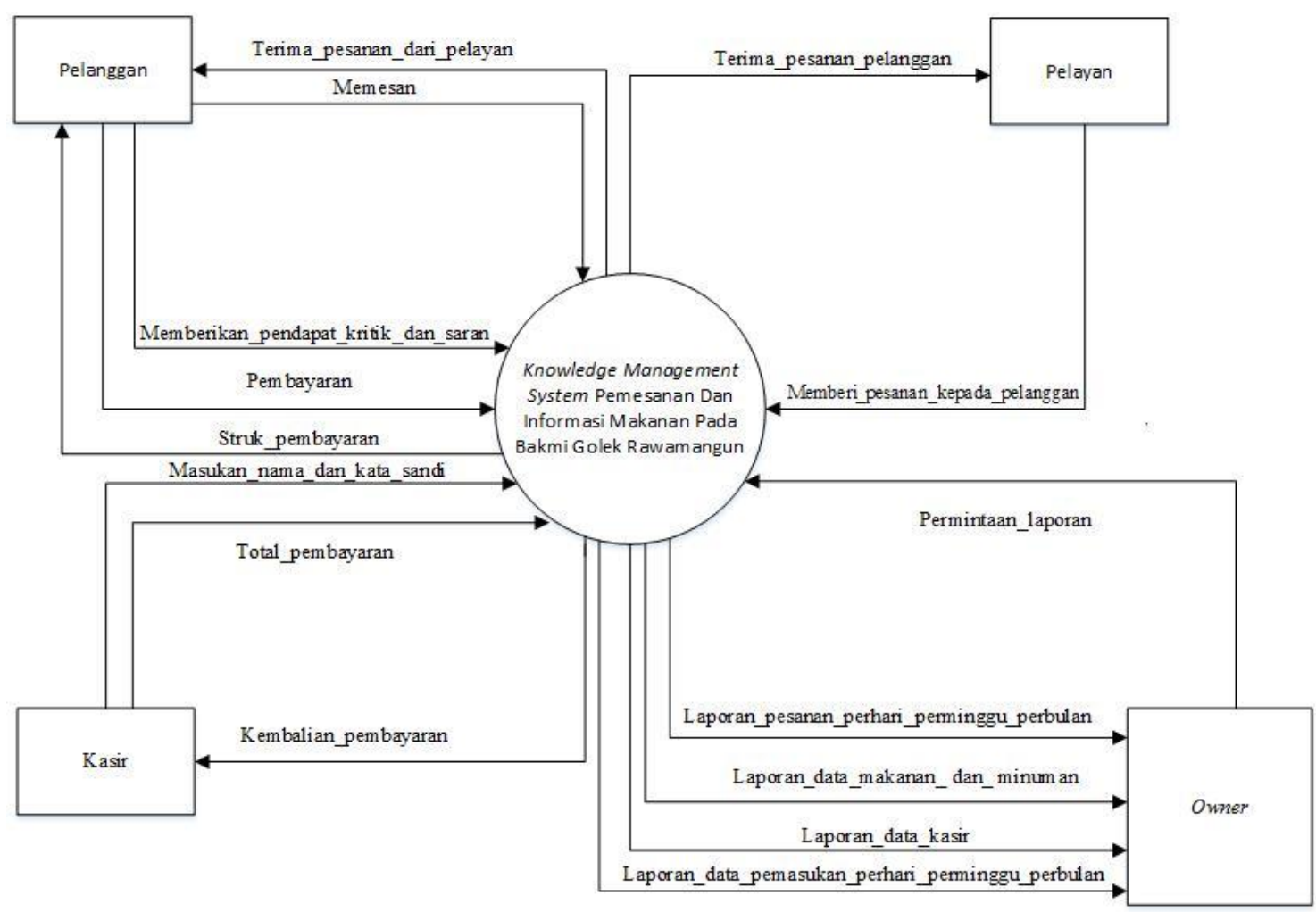

Gambar 2. Diagram Konteks yang Diusulkan

\section{Proses Pemesanan}

a. Bagian kasir memasukkan nama dan kata sandi, jika belum terdaftar bisa buat baru dengan memasukkan nama lengkap, kata sandi, nomor telepon dan juga alamat pemilik akun untuk proses pendaftaran.

b. Pelanggan tidak memerlukan akun karena sudah bisa langsung akses untuk memesan makanan yang dipesan.

2. Proses FAQ

a. Pelanggan bisa melakukan penilaian dan memberikan pendapat terhadap Bakmi Golek Rawamangun yang nantinya akan diketahui oleh kasir Bakmi Golek Rawamangun.

b. Pelanggan bisa memberikan kritik dan saran yang nantinya akan diketahui oleh kasir.

3. Proses Pembayaran

a. Pelanggan melakukan pembayaran melalui kasir yang kemudian kasir akan mencetak bukti struk pesanan. 


\section{Proses Laporan}

a. Proses yang terakhir yaitu pencetakan laporan pesanan, yaitu laporan pesanan perhari/perminggu/perbulan, laporan data makanan dan minuman, laporan data kasir, dan laporan data pemasukan perhari/perminggu/perbulan. Laporan-laporan ini yang nantinya akan diberikan oleh owner.

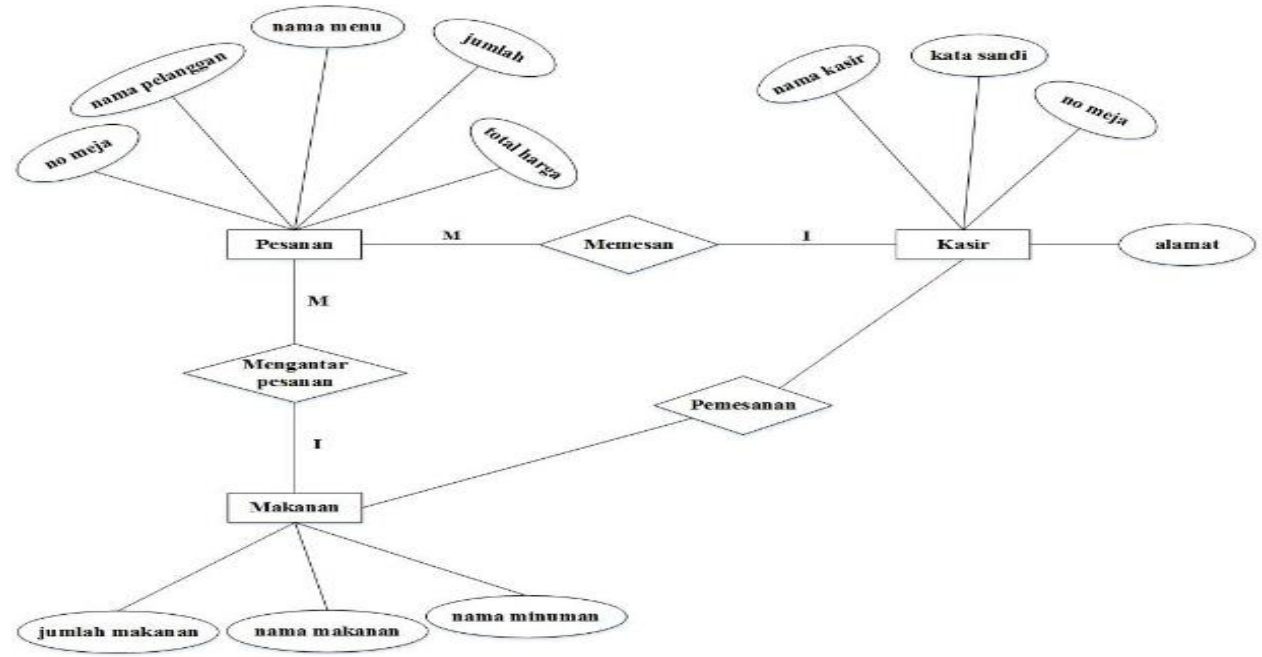

Gambar 3. Entity Relationship Diagram

ERD adalah pemodelan awal basis data yang dikembangkan berdasarkan teori himpunan dalam bidang matematika. ERD digunakan untuk pemodelan basis data relasional [14].

Dalam alur ERD ini penulis akan menjelaskan bagaimana alur dari basis datanya, yaitu:

1. Pelanggan mengisi form pesanan dengan memasukkan nama, lalu klik menu yang ingin dipesan, jumlah pesanan, lalu akan keluar berapa total harga yang sudah dipesan pelanggan.

2. Selanjutnya kasir akan login untuk masuk ke aplikasi dan mengecek pesanan pelanggan.

3. Setelah pesanan sudah diproses maka pelayan akan mengantarkan makanan yang tadi sudah dipesan pelanggan.

Normalisasi adalah sebuah teknik untuk menghasilkan sebuah set relasi dengan properti yang diinginkan, dengan diberikan data perusahaan yang dibutuhkan [15]. Proses ini merupakan hubungan antar file yang satu dengan yang lainnya yang saling berhubungan. Adapun gambarannya adalah sebagai berikut:

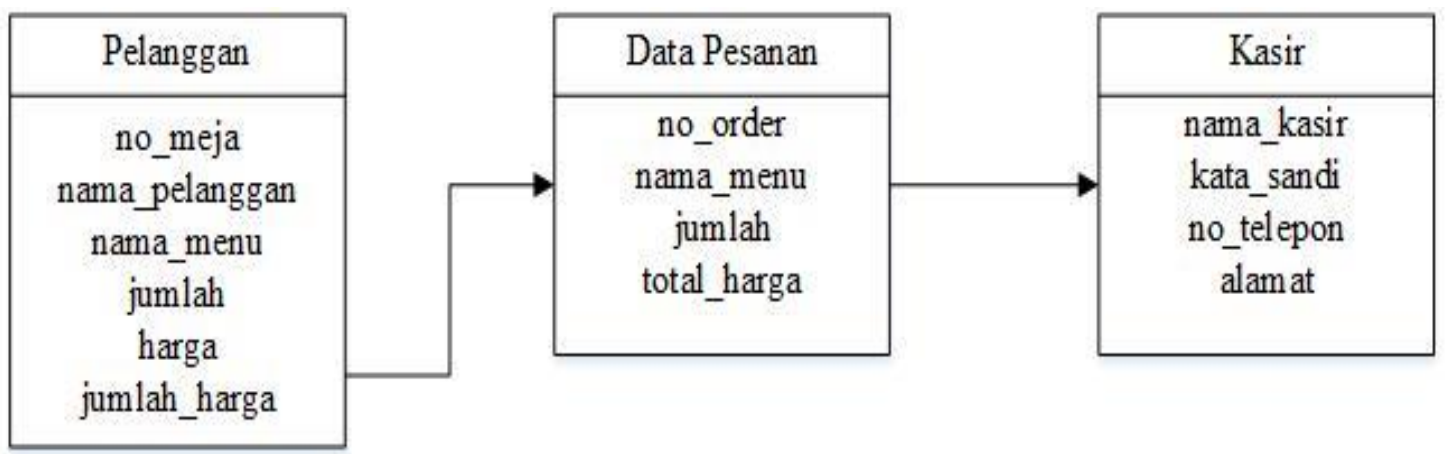

Gambar 4. Normalisasi Tahap Satu (1 NF) 


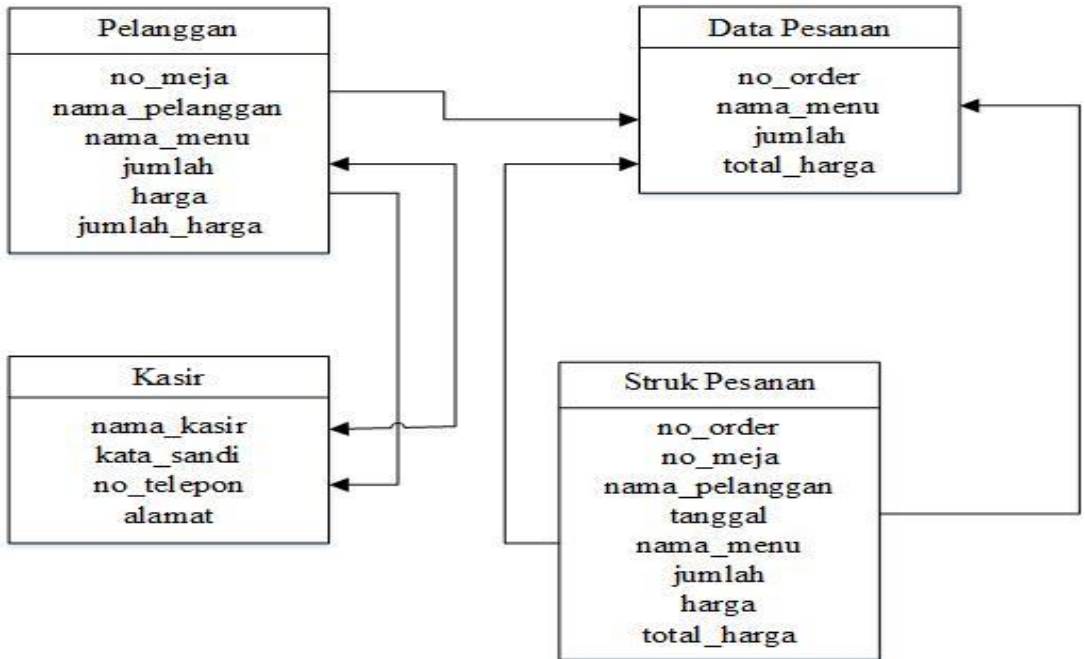

Gambar 5. Normalisasi Tahap Kedua (2 NF)

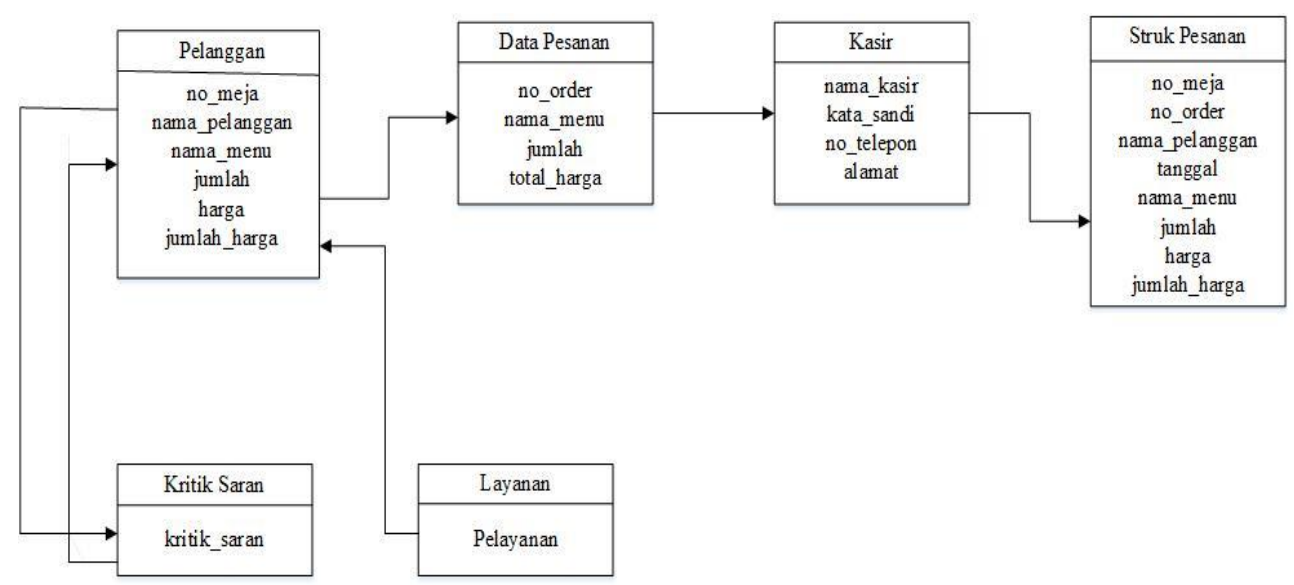

Gambar 6. Normalisasi Tahap Ketiga (3 NF)

\section{Tampilan Menu Login}

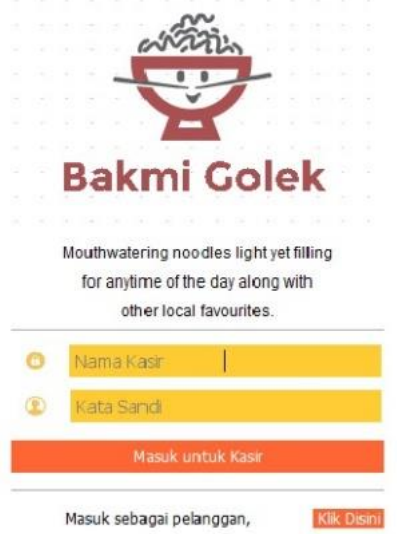

Gambar 7. Tampilan Menu Login 
Tampilan ini terdapat pada awal program. Menu login digunakan sebagai kunci sebelum kasir memasuki program utama. Kasir dapat memasukkan nama dan kata sandi dengan tepat, maka menu utama akan tampil dan program siap untuk dijalankan.

\section{Tampilan Menu Kasir}

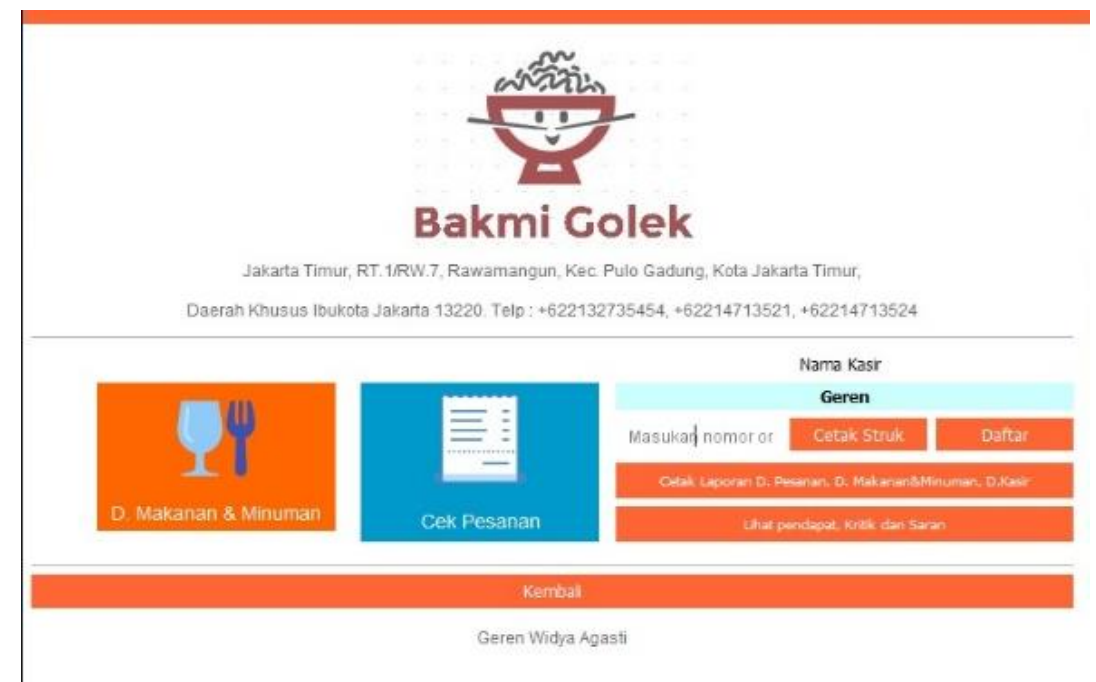

Gambar 8. Tampilan Menu Kasir

Tampilan ini terdapat di dalam menu kasir. Tampilan ini akan muncul setelah kasir login untuk masuk. Tampilan menu kasir ini terdapat fitur untuk menginput data makanan dan minuman, mengecek pesanan pelanggan, mencetak struk, melihat laporan-laporan dan melihat pendapat, kritik dan saran dari pelanggan.

\section{Tampilan Informasi Menu}

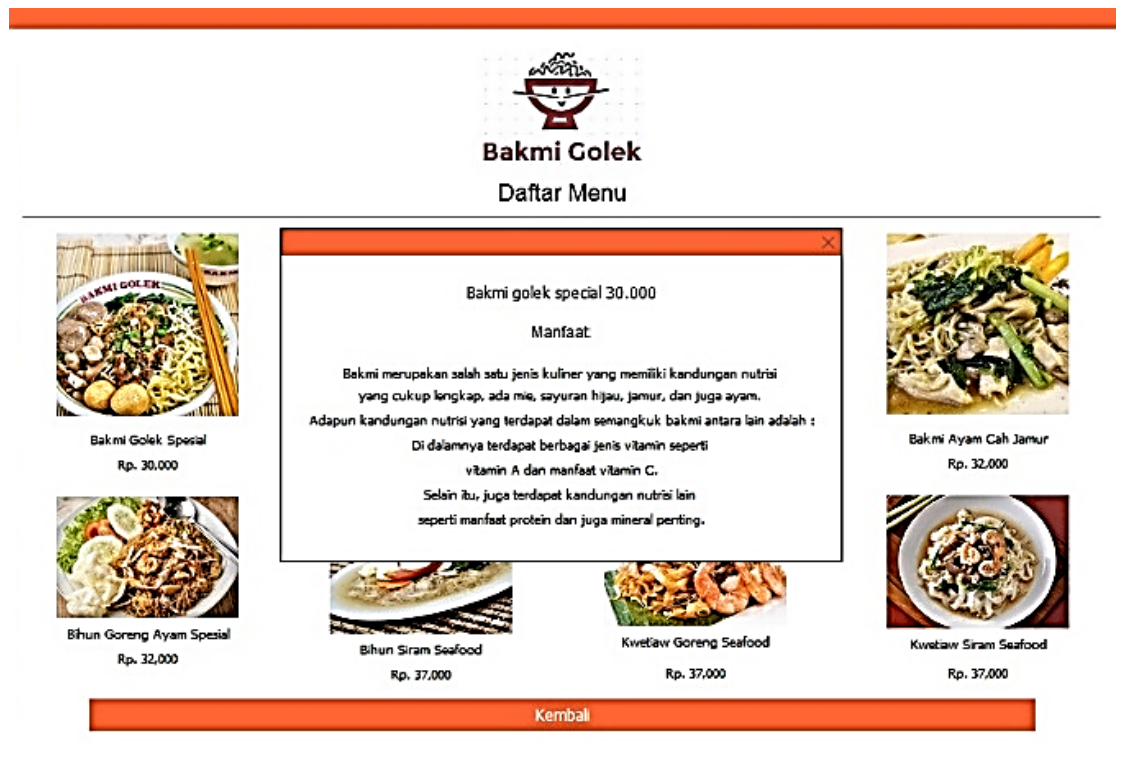

Gambar 9. Tampilan Informasi Menu 
Pada tampilan ini terdapat beberapa menu yang ada di sistem. Pelanggan dapat memilih dan melihat beberapa manfaat yang ada di setiap makanan. Sistem ini menggunakan salah satu SECI Model yaitu Externalization, dalam proses ini pengetahuan mengenai bahan-bahan makanan dan manfaatnya diekspresikan dan diterjemahkan menjadi sebuah konsep sehingga dapat dengan mudah dimengerti oleh pelanggan.

\section{Tampilan Form Pemesanan}

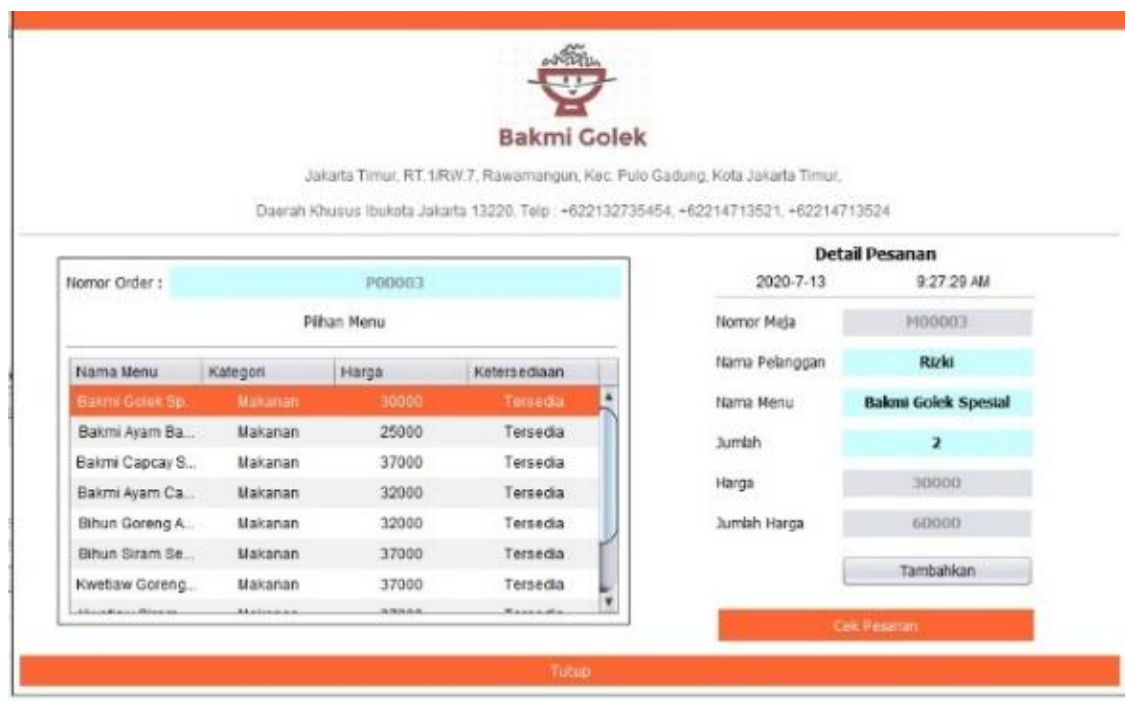

Gambar 10. Tampilan Form Pemesanan

Pada tampilan pemesanan ini pelanggan akan mengisi beberapa form untuk membuat pesanan seperti nama pelanggan, nama menu dan jumlah pesanan untuk mengetahui apa saja yang akan dipesan dan mengetahui jumlah harga yang dipesan.

\section{Tampilan Fitur FAQ}

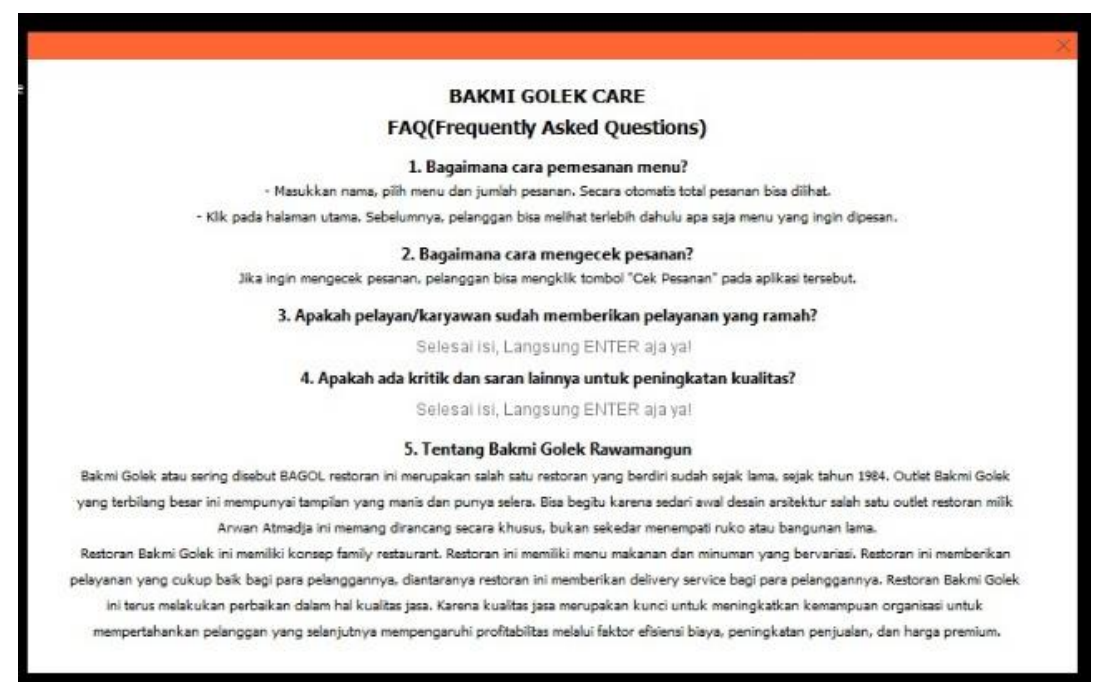

Gambar 11. Tampilan Fitur FAQ 
Tampilan imi berguna untuk melihat tata cara pemesanan dan pelanggan bisa memberikan pendapat, kritik dan saran. Sistem ini menggunakan salah satu SECI Model yaitu Socialization, dalam hal ini mengartikan adanya sosialisasi antar sumber dan penerima pengetahuan dengan cara pelanggan memberikan masukan dan kritikan agar pihak Bakmi Golek Rawamangun mengetahi hal tersebut.

\section{Tampilan Struk Pesanan}

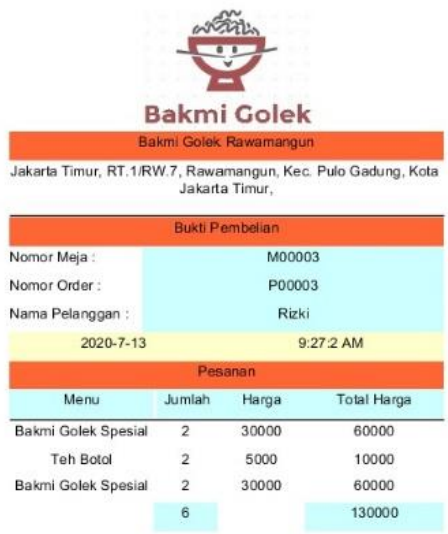

Gambar 12. Tampilan Struk Pesanan

Tampilan ini berfungsi untuk bukti pembelian pesanan dari pelanggan. Struk pembelian menjadi bukti bahwa produk yang dibeli sudah selesai diterima.

\section{Uji Coba Pengujian Sistem Dengan Blackbox Testing}

Tabel 3. Pengujian Pada Form Pemesanan

\begin{tabular}{|l|l|l|l|}
\hline No & Skenario Pengujian & \multicolumn{1}{c|}{ Hasil Yang Diterapkan } & Kesimpulan \\
\hline 1 & $\begin{array}{l}\text { Klik form memesan } \\
\text { lalu Input Form } \\
\text { Pemesanan, } \\
\text { selanjutnya klik } \\
\text { tombol Tambahkan }\end{array}$ & $\begin{array}{l}\text { Sistem tidak akan dapat } \\
\text { menyelesaikan prosesnya apabila } \\
\text { kolom ada yang tidak terisi } \\
\text { (kosong), maka akan menampilkan } \\
\text { pesan "Pesanan Salah" namun } \\
\text { apabila data terisi semua "Berhasil } \\
\text { Memesan" }\end{array}$ & Sesuai \\
\hline 2 & $\begin{array}{l}\text { Klik data yang akan } \\
\text { diedit pada tabel, lalu } \\
\text { klik tombol Edit }\end{array}$ & $\begin{array}{l}\text { Sistem tidak akan dapat } \\
\text { menyelesaikan prosesnya apabila } \\
\text { kolom ada yang tidak terisi } \\
\text { kosong), maka akan menampilkan } \\
\text { pesan "Data Isian Ada Yang } \\
\text { Kosong" namun apabila data terisi } \\
\text { semua "Data Berhasil Diedit" }\end{array}$ & Sesuai \\
\hline
\end{tabular}


Tabel 4. Cetak Struk Pesanan

\begin{tabular}{|l|l|l|l|}
\hline No & Skenario Pengujian & \multicolumn{1}{|c|}{ Hasil Yang Diterapkan } & Kesimpulan \\
\hline 1 & Klik masukkan nomor & $\begin{array}{l}\text { Sistem tidak akan dapat } \\
\text { menyelesaikan prosesnya apabila } \\
\text { kolom ada yang tidak terisi } \\
\text { (kosong), maka akan menampilkan } \\
\text { pesan "The document has no } \\
\text { pages" namun apabila data terisi } \\
\text { semua bukti struk akan keluar } \\
\text { secara otomatis }\end{array}$ & Sesuai \\
\hline 2 & $\begin{array}{l}\text { Klik data yang akan } \\
\text { diisi pada tabel, lalu } \\
\text { klik tombol cetak struk }\end{array}$ & $\begin{array}{l}\text { Sistem tidak akan dapat } \\
\text { menyelesaikan prosesnya apabila } \\
\text { kolom ada yang tidak terisi } \\
\text { (kosong), maka akan menampilkan } \\
\text { "The document has no pages" } \\
\text { namun apabila data terisi bukti } \\
\text { struk otomatis akan keluar }\end{array}$ & Sesuai \\
\hline
\end{tabular}

Tabel 5. Cetak Laporan

\begin{tabular}{|l|l|l|l|}
\hline No & Skenario Pengujian & \multicolumn{1}{c|}{ Hasil Yang Diterapkan } & Kesimpulan \\
\hline 1 & $\begin{array}{l}\text { Klik tabel pada } \\
\text { tanggal. Jika tanggal } \\
\text { sudah ditentukan } \\
\text { makapilih laporan } \\
\text { yang ingin dicetak }\end{array}$ & $\begin{array}{l}\text { Sistem tidak akan dapat } \\
\text { menyelesaikan prosesnya apabila } \\
\text { alur tanggalnya salah, maka akan } \\
\text { menampilkan pesan "The document } \\
\text { has no pages" namun apabila } \\
\text { tanggal terisi dengan benar maka } \\
\text { laporan akan tercetak }\end{array}$ & \\
& & Sesuai & \\
\hline
\end{tabular}

\section{KESIMPULAN DAN SARAN}

\subsection{Kesimpulan}

Berdasarkan penelitian yang penulis lakukan, maka dapat disimpulkan bahwa:

1. Aplikasi ini dibuat dengan harapan dapat mempermudah pihak Bakmi Golek Rawamangun dan pelanggan dalam menjalankan aktivitas jual beli.

2. Dengan adanya knowledge management system ini pemesanan dapat dilakukan secara cepat dan efisien dan pelanggan bisa mengetahui apa saja manfaat dan bahan dari setiap menu makanan.

3. Dengan adanya sistem aplikasi ini pengguna tidak membutuhkan waktu yang lama dalam pencarian data yang disimpan.

4. Penerapan sistem ini nantinya akan menghasilkan laporan-laporan seperti laporan pesanan perhari, minggu, bulan dan laporan data makanan dan minuman, laporan data kasir dan laporan data pemasukan perhari/permingu/perbulan yang dapat digunakan saat dibutuhkan oleh pihak Bakmi Golek Rawamangun. 


\subsection{Saran}

Penulis menyadari masih banyak kekurangan dari penelitian yang penulis lakukan. Pengembangan yang dapat dilakukan dari penelitian yang penulis lakukan diantaranya:

1. Belum adanya fitur untuk memanggil pelayan tanpa pelanggan harus memanggil secara langsung.

2. Dalam aplikasi ini masih ada kurangnya laporan-laporan yang ingin direalisasikan lagi.

3. Diharapkan penelitian ini dapat dijadikan sebagai bahan bacaan ataupun referensi yang bermanfaat bagi mahasiswa yang berminat mengambil pembahasan yang sama.

\section{UCAPAN TERIMAKASIH}

Penulis mengucapkan terima kasih kepada seluruh jajaran dan pihak Bakmi Golek Rawamangun yang telah membantu dalam penelitian dan memberi informasi serta bahan yang diperlukan dalam penulisan artikelini.

\section{DAFTAR PUSTAKA}

[1] Hizair, Kamus Lengkap Bahasa Indonesia. Jakarta: Tamer, 2013.

[2] A. Pratiwi and L. P. Hansugian, "Knowledge Management System pada PT. TASPEN KCU Bandung," Ultim. InfoSys J. Ilmu Sist. Inf., vol. 9, no. 2, 2018.

[3] F. Latifah, I. Saefudin, P. Studi, K. Akutansi, P. Studi, and T. Informatika, "Perancangan Aplikasi Jejaring Sosial Alumi," J. PETIR, vol. 11, no. 2, pp. 178-190, 2018.

[4] G. Arumningtyas, P. Irfansyah, and S. Harris, "Perancangan Sistem Informasi Akademik Bimbel Sinar Ilmu," Systematics, vol. 1, no. 2, pp. 110-115, 2019.

[5] S. Mardhotillah, "Analisis Perancangan Knowledge Management System Berbasis WEB dan WAP: Studi Kasus SMAN 4,” UIN Syarif Hidayatullah Jakarta, 2011.

[6] H. Dhika and R. Awaldi, "Sistem Pemesanan Makanan dan Minuman di Osaka Ramen Depok Berbasis Java," Fakt. Exacta, vol. 12, no. 4, pp. 262-271, 2020.

[7] M. R. Ridha, "Analisa Dan Desain Model Sistem Informasi Perpustakaan Universitas Islam Indragiri,” Sist. J. Sist. Inf., vol. 6, no. 3, 2017.

[8] M. Amar Maratin, R. Amelia Sawitri, T. Tinaliah, and N. Wijaya, "APLIKASI PEMESANAN MAKANAN DAN MINUMAN PADA RUMAH MAKAN PINDANG RAJO."

[9] E. R. Ningsih, "Knowledge management system (kms) dalam meningkatkan inovasi lppm perguruan tinggi," EVOLUSI J. Sains dan Manaj., vol. 1, no. 1, 2013.

[10] A. Muharto \& Ambarita, "Metode Penelitian Sistem Informasi: Mengatasi Kesulitan Mahasiswa Dalam Menyusun Proposal Penelitian,” Deep. Yogyakarta, 2016.

[11] S. L. Hoe, "Tacit knowledge, Nonaka and Takeuchi SECI model and informal knowledge processes," Int. J. Organ. theory Behav., vol. 9, no. 4, p. 490, 2006.

[12] H. Tolle, A. Pinandito, A. P. Kharisma, and R. K. Dewi, Pengembangan Aplikasi Perangkat Bergerak. Malang: Universitas Brawijaya Press, 2016.

[13] Z. S. Jamil, D. Irfan, and T. Sriwahyuni, "Perancangan Sistem Informasi Pemetaan Fasilitas Kesehatan Kota Padang Berbasis Web Dengan Memanfaatkan Google Maps API," $J$. Vokasional Tek. Elektron. Inform., vol. 3, no. 1, pp. 1-10, 2015.

[14] R. A. Sukamto and M. Shalahuddin, Rekayasa Perangkat Lunak Terstruktur Dan Berorientasi Objek. Bandung: Informatika., 2013.

[15] G. K. Sugiarto, "Analisa dan perancangan sistem informasi perpustakaan sekolah kristen satya wacana salatiga," 2013. 